\title{
Pengaruh Motivasi dan Kepuasan Kerja terhadap Prestasi Kerja Dosen Universitas Kadiri
}

\author{
Yogi Yunanto \\ Fakultas Ekonomi Universitas Kadiri \\ email: yunantoyogi@gmail.com \\ Sasi Utami \\ Fakultas Ekonomi Universitas Kadiri \\ email: sasi_utami@gmail.com
}

\begin{abstract}
Abstrak
Organisasi merupakan sistem kegiatan manusia yang bekerja sama. Sesuai dengan itu, organisasi dikatakan sebagai suatu koordinasi rasional kegiatan sejumlah orang untuk mencapai beberapa tujuan umum melalui pembagian pekerjaan dan fungsi melalui hierarki otoritas dan tanggung jawab. Jenis penelitian ini adalah penelitian analitik korelasional. Dengan menggunakan model SEM. Hasil penelitian menunjukkan bahwa motivasi berpengaruh terhadap kepuasan kerja dosen, motivasi juga berpengaruh terhadap prestasi dosen, dan kepuasan memberikan pengaruh terhadap prestasi dosen.
\end{abstract}

Kata kunci: Motivasi, Kepusan Kerja, Prestasi Kerja.

\begin{abstract}
Organizations is a coordination of human system activities, in accordance with activities of a group of people to accomplish goals through job and function distribution hierarchy of authority. This research is correlational analythic research, using the SEM method and the sample of 100 respondents who are lecture of Kadiri University, showing result in which the motivation influence work satisfaction of the lectures; the motivation influence work achievements and the work satisfaction influence work achievement of the lecture in Kadiri University.
\end{abstract}

Keywords: Motivation, Work Satisfaction, work achievement.

\section{PENDAHULUAN}

Organisasi merupakan sistem dan kegiatan manusia yang bekerja sama. Sejalan dengan itu, organisasi dikatakan sebagai suatu koordinasi rasional kegiatan sejumlah orang untuk mencapai beberapa tujuan umum melalui pembagian pekerjaan dan fungsi melalui hierarki otoritas dan tanggung jawab. Hal tersebut menggambarkan bahwa organisasi mempunyai karakteristik tertentu yang struktur dan tujuannya saling berhubungan serta tergantung pada komunikasi manusia untuk mengkoordinasikan aktivitas dalam organisasi tersebut. Hal ini dapat dikatakan bahwa organisasi mempunyai 
tujuan agar dapat memenuhi kebutuhan hidupnya sehingga memperoleh kepuasan. Oleh sebab itu, organisasi menghadapkan para pegawai dapat berprestasi dan mampu menciptakan situasi dan kondisi yang kondusif sehingga pegawai tidak akan mengalami kejenuhan, kebosanan, dan malas bekerja yang mengakibatkan semangat kerja menjadi menurun. Hal ini disebabkan apabila semangat kerja menurun dapat mengakibatkan prestasi kerja pegawai juga mengalami penurunan. Prestasi kerja pegawai yang menurun akan mengakibatkan kerugian pada organisasi.

Pekerjaan dapat lebih cepat dan tepat diselesaikan tanpa mengurangi kedisiplinan yang ada jika didukung oleh peran serta seorang pimpinan. Dalam hal ini pimpinan harus selalu memberikan arahan, membina, dan memotivasi bawahan dalam menyelesaikan pekerjaan untuk mencapai tujuan organisasi. Hal tersebut selalu diupayakan oleh pimpinan dengan memberikan motivasi dan keseimbangan upah atas hasil pekerjaan pegawai, dalam hal ini adalah dosen.

Motivasi perlu dilaksanakan suatu organisasi, dimana seluruh aktivitas dan tugastugas jika didasarkan pada motivasi yang tinggi maka prestasi kerja juga akan menjadi tinggi dan sebaliknya. Agar seseorang mau melakukan sesuatu pekerjaan, orang tersebut memerlukan motivasi. Motivasi merupakan hal/sesuatu yang mendorong seseorang melakukan berbuat sesuatu. Motivasi suatu individu (motivasi intrinsik) dan dapat timbul dari luar individu (motivasi ekstrinsik). Dan keduanya mempunyai pengaruh terhadap perilaku dan prestasi kerja. Dengan demikian dapat diketahui motivasi berpengaruh terhadap prestasi kerja pegawai.

Kepuasan kerja mencerminkan perasaan seseorang terhadap pekerjaannya. Hal ini tampak dalam sikap positif dosen terhadap pekerjaan dan segala sesuatu yang dihadapi di lingkungan kerjanya. Setiap dosen memiliki tingkat kepuasan yang berbeda-beda sesuai dengan nilai yang berlaku pada dirinya. Semakin banyak aspek dalam pekerjaan yang sesuai dengan keinginan dan aspek-aspek diri individu, maka ada kecenderungan semakin tinggi tingkat kepuasan kerjanya. Kepuasan kerja dapat mengakibatkan pengaruh terhadap tingkat turnover dan tingkat absensi terhadapkesehatan fisik dan mental dosen serta tingkat kelambanan.

Kepuasan kerja di dalam diri individu dapat berasal dari dalam diri individu sendiri, namun pengaruh dari lingkungan eksternal (luar diri) berperan dalam membentuk perilaku bertahan atau keluar, berupa sesuatu yang diterima individu dari lingkungan 
pekerjaannya. Pembahasan mengenai kepuasan kerja perlu didahului oleh penegasan bahwa masalah kepuasan kerja bukanlah hal yang sederhana, baik dalam arti konsepnya maupun dalam arti analisisnya, karena kepuasan kerja mempunyai konotasi yang beraneka ragam. Meskipun demikian tetap relevan untuk menyatakan bahwa kepuasan kerja merupakan suatu cara pandang seseorang, baik yang bersifat positif maupun negatif, tentang pekerjaannya.

Prestasi kerja dosen berarti prestasi atau kontribusi yang diberikan oleh dosen dalam melaksanakan tugas dan tanggung jawab serta fungsinya sebagai dosen di institusi pendidikan. Selain itu, prestasi kerja dibatasi sebagai hasil dari perilaku kerja dosen yang menunjang tercapainya output atau prestasi dan berkaitan dengan usaha untuk menyelesaikan tugasnya pada periode waktu tertentu. Hasil yang tercermin pada perilaku tersebut dipengaruhi antara lain oleh motivasi (Mangkunegara, 2005). Indikator yang perlu diperhatikan pada prestasi kerja adalah kualitas kerja, kuantitas kerja, disiplin kerja, inisiatif, dan kerjasama (Nasution, 2005).

\section{TINJAUAN PUSTAKA}

\section{Motivasi Kerja}

Motivasi adalah keadaan kejiwaan dan sikap mental manusia yang memberikan energi, mendorong kegiatan dan mengarahkan perilaku kearah mencapai kebutuhan yang memberi kepuasan (Berelson dan Stainer, 2003).

\section{Kepuasan Kerja}

Menurut Robbins (2003) kepuasan kerja adalah sikap umum terhadap pekerjaan seseorang yang menunjukkan perbedaan antara jumlah penghargaan yang diterima pekerja dan jumlah yang mereka yakini seharusnya mereka terima.

\section{Prestasi Kerja}

Prestasi kerja adalah hasil upaya seseorang yang ditentukan oleh kemampuan karakteristik pribadinya serta persepsi terhadap perannya terhadap pekerjaan itu (Sutrisno, 2011).

\section{Pengaruh Motivasi Terhadap Kepuasan Kerja Dosen}

seorang dosen yang bekerja dalam suatu institusi pendidikan tentu dilandasi dengan keinginan untuk mencukupi kebutuhannya baik kebutuhan akan sandang, pangan dan papan. 


\section{Pengaruh motivasi terhadap prestasi kerja}

Kinerja merupakan hasil kerja secara kualitas dan kuantitas yang dapat dicapai oleh seorang pegawai dalam melaksanakan tugas sesuai dengan tanggung jawab yang diberikan kepadanya. Menurut A.A Anwar Prabu Mangkunegara (2005: 9)

\section{Pengaruh Kepuasan Kerja Terhadap Prestasi Kerja}

Handoko mengatakan "Secara historis, sering dianggap bahwa para karyawan yang mendapatkan kepuasan kerja akan melaksanakan pekerjan dengan lebih baik. Dalam banyak kasus, memang sering ada hubungan positif antara kepuasan tinggi dan prestasi kerja tinggi, tetapi tidak selalu cukup kuat dan berarti (signifikan)”.

\section{Pengaruh Motivasi Terhadap Prestasi Kerja Melalui Kepuasan Kerja}

Adapun menurut Strauss dan Sayless, "Kepuasan kerja juga penting untuk aktualisasi diri. Karyawan yang tidak memperoleh kepuasan kerja tidak akan pernah mencapai kematangan psikologis, dan pada gilirannya akan menjadi prustasi.

\section{METODE PENELITIAN}

\section{Lokasi Penelitian}

Penelitian ini akan dilakukan di Universitas Kadiri Jl Selomangleng No 1 Kota Kediri.

\section{Jenis Penelitian}

Jenis penelitian ini adalah penelitian analitik korelasional. Di dalam Walpole (1995) analisis korelasi adalah metode statistik yang digunakan untuk mengukur besarnya hubungan linier antara dua variabel atau lebih.

\section{Populasi dan Sampel}

Populasi dalam penelitian ini adalah seluruh dosen Universitas Kadiri sebanyak 208, sedangkan sampel dalam penelitian ini adalah sebagian populasi. Besarnya sampel menggunakan sampel minimal yaitu sebanyak 100 dosen.

\section{Jenis dan Sumber Data}

Jenis data yang digunakan adalah data kuantitatif. Data yang digunakan dalam penelitian ini adalah data primer dan data sekunder. Data primer diperoleh dari penyebaran angket kepada responden. Sementara data sekunder digunakan untuk mendukung data primer, berupa data administratif yang diperoleh dari dokumen Universitas Kadiri. 


\section{Metode Pengumpulan Data}

Dalam penelitian ini penulis memilih beberapa teknik sesuai dengan desain penelitian yang digunakan, yakni :

a. Kuesioner.

Kuesioner ini dimaksudkan untuk memperoleh informasi secara tertulis dari responden berkaitan dengan variabel penelitian. Tujuan utama dari pembuatan kuesioner ini adalah memperoleh informasi yang relevan dengan tujuan survey, memperoleh informasi dengan reliabilitas dan validitas setinggi mungkin.

b. Dokumentasi.

Studi dokumentasi adalah mengumpulkan informasi dengan mempelajari sumber tertulis untuk memperoleh data sekunder dari masing-masing institusi yang menjadi obyek penelitian yang ada hubungannya dengan penelitian ini (Arikunto, 2006)

\section{Metode Analisis Data}

\section{SEM}

SEM sebuah permodelan lengkap pada dasarnya terdiri dari model pengukuran (Measurement Model) dan Structural Model atau Causal Model. Adapaun beberapa langkah yang dilakukan untuk membentuk model adalah sebagai berikut: digunakan untuk mengetahui pengaruh dari variabel independen $(\mathrm{X})$ terhadap variabel dependen $(\mathrm{Y})$.

Melalui SEM ini juga bisa diketahui keeratan hubungan atau korelasi (R) antara variabel-variabel bebas dan variabel terikat, dimana nilai koefisien korelasi (R) yang mendekati 1 menunjukan tingkat keeratan hubungan yang semakin tinggi antara kedua jenis variabel itu. SEM juga dapat menunjukan besaran kontribusi dari variabel-variabel bebas dalam menjelaskan perubahan atau fluktuasi yang terjadi atas variabel terikat, dimana nilai koefisien determinasi $\left(\mathrm{R}^{2}\right)$ yang mendekati 1,0 menunjukan besaran kontribusi dari variabel-variabel bebas terhadap perubahan variabel terikat adalah mendekati 100\% (Ghozali 2007)

Uji Hipotesis

Untuk menguji hipotesis pertama dalam penelitian ini digunakan uji $\mathrm{F}$, yaitu pengujian koefisien secara simultan dengan cara membandingkan probability value-nya dengan alpha $(\alpha)$ sebesar $5 \%$ atau 0,05 . Kriteria yang digunakan adalah jika nilai 
probability value (Sig)-nya lebih kecil dari $\alpha(0,05)$ berarti hipotesis pertama diterima, sebaliknya jika nilai probability value (Sig)-nya lebih besar dari $\alpha(0,05)$ berarti hipotesis pertama ditolak (Ghozali 2007).

Berikutnya, untuk menguji hipotesis kedua dalam penelitian ini digunakan uji t yaitu pengujian koefisien secara parsial dengan cara membandingkan probability valuenya dengan alpha $(\alpha)$ sebesar 5\% atau 0,05 . Kriteria yang digunakan adalah jika nilai probability value (Sig)-nya lebih kecil dari $\alpha(0,05)$ berarti hipotesis kedua diterima, sebaliknya jika nilai probability value (Sig)-nya lebih besar dari $\alpha(0,05)$ berarti hipotesis kedua ditolak (Ghozali 2007)

Terakhir untuk menguji hipotesis ketiga dalam penelitian ini digunakan perbandingan angka standardized coefficients (Beta) antar variabel bebas, kriteria yang digunakan adalah jika terdapat suatu variabel bebas memiliki angka standardized coefficients (Beta) yang paling besar dibandingkan variabel bebas yang lain, maka variabel bebas tersebut dinyatakan memiliki pengaruh paling besar atau dominan terhadap variabel terikat (Ghozali 2007)

\section{HASIL DAN PEMBAHASAN}

\section{Hasil analisis dengan SMARTPLS}

\section{Gambar 1 Tampilan Hasil SmartPls}

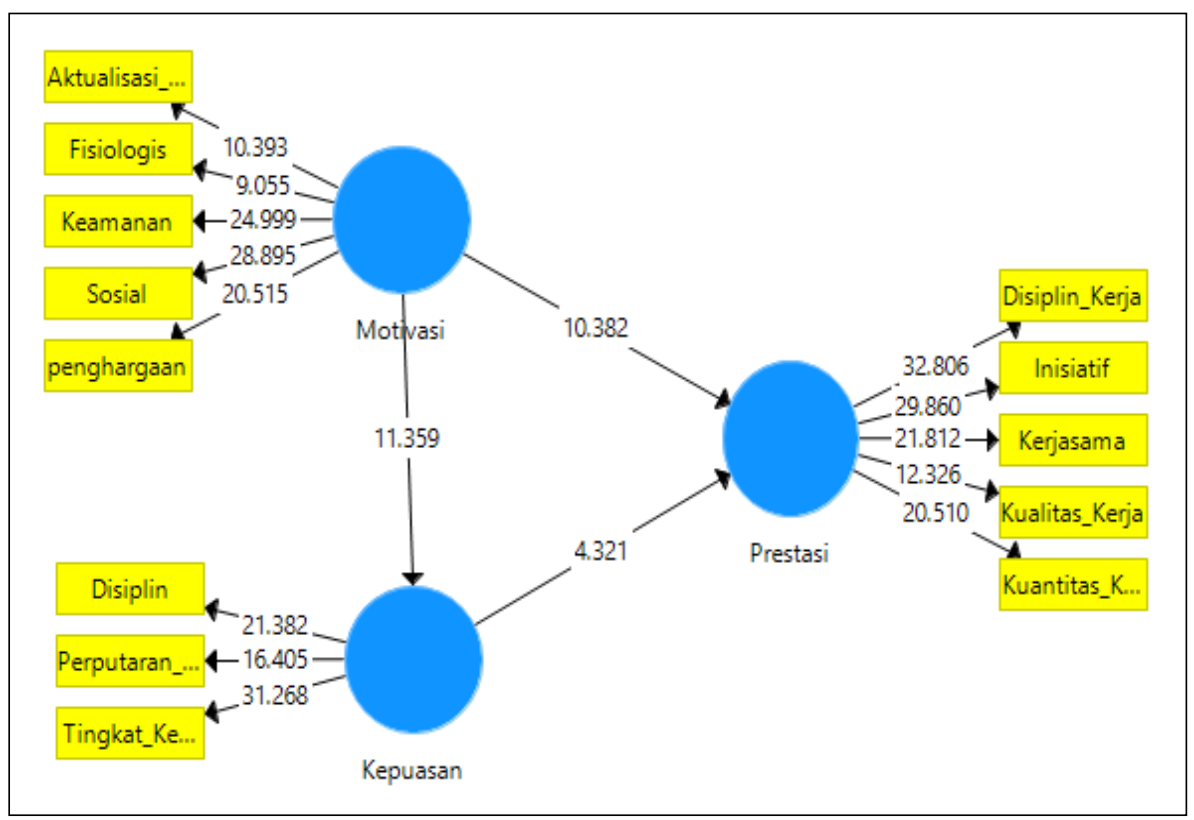

Berdasarkan gambar diatas dapat dilihat bahwa Motivasi memiliki berpengaruh terhadap prestasi. Kesimpulan ini diambil dengan mempertimbangkan nilai $\mathrm{T}$ sebesar 
10.382 dimana nilai ini lebih besar dari 1.96. Variabel motivasi juga berpengaruh terhadap kepuasan dengan nilai $\mathrm{T}$ sebesar 11.359. Variabel Kepuasan juga memiliki pengaruh yang signifikan terhadap prestasi karena nilai T nya sebesar 4.321 lebih besar dari 1.96.

Tabel 1 Motivasi Memiliki Pengaruh tidak Langsung ke Prestasi.

\begin{tabular}{|l|r|r|r|r|r|}
\hline & $\begin{array}{l}\text { Original } \\
\text { Sample } \\
(\mathbf{O})\end{array}$ & $\begin{array}{l}\text { Sample } \\
\text { Mean (M) }\end{array}$ & $\begin{array}{l}\text { Standard } \\
\text { Deviation } \\
\text { (STDEV) }\end{array}$ & $\begin{array}{l}\text { T Statistics } \\
(\mid \mathbf{O} / \text { STDEV } \mid)\end{array}$ & P Values \\
\hline Kepuasan -> Prestasi & 0.2967 & 0.2929 & 0.0687 & 4.3213 & 0.0000 \\
\hline Motivasi -> Kepuasan & 0.6809 & 0.6907 & 0.0599 & 11.3594 & 0.0000 \\
\hline Motivasi -> Prestasi & 0.6322 & 0.6371 & 0.0609 & 10.3818 & 0.0000 \\
\hline
\end{tabular}

\begin{tabular}{|l|r|r|r|r|r|}
\hline & \multicolumn{1}{|l|}{$\begin{array}{l}\text { Original } \\
\text { Sample (O) }\end{array}$} & $\begin{array}{l}\text { Sample } \\
\text { Mean } \\
(\mathbf{M})\end{array}$ & $\begin{array}{l}\text { Standard } \\
\text { Deviation } \\
\text { (STDEV) }\end{array}$ & $\begin{array}{l}\text { T Statistics } \\
(\mid \mathbf{O} / \text { STDEV })\end{array}$ & P Values \\
\hline Aktualisasi_Diri <- Motivasi & 0.2308 & 0.2288 & 0.0190 & 12.1744 & 0.0000 \\
\hline Disiplin <- Kepuasan & 0.4173 & 0.4167 & 0.0354 & 11.8011 & 0.0000 \\
\hline Disiplin_Kerja <- Prestasi & 0.2517 & 0.2518 & 0.0157 & 15.9830 & 0.0000 \\
\hline Fisiologis <- Motivasi & 0.2297 & 0.2293 & 0.0222 & 10.3562 & 0.0000 \\
\hline Inisiatif <- Prestasi & 0.2821 & 0.2812 & 0.0208 & 13.5534 & 0.0000 \\
\hline Keamanan <- Motivasi & 0.2566 & 0.2563 & 0.0180 & 14.2789 & 0.0000 \\
\hline Kerjasama <- Prestasi & 0.2334 & 0.2319 & 0.0145 & 16.0961 & 0.0000 \\
\hline Kualitas_Kerja <- Prestasi & 0.2102 & 0.2103 & 0.0147 & 14.3097 & 0.0000 \\
\hline Kuantitas_Kerja <- Prestasi & 0.2300 & 0.2305 & 0.0144 & 15.9596 & 0.0000 \\
\hline $\begin{array}{l}\text { Perputaran_Tenaga_Kerja <- } \\
\text { Kepuasan }\end{array}$ & 0.3785 & 0.3775 & 0.0305 & 12.4080 & 0.0000 \\
\hline Sosial <- Motivasi & 0.2872 & 0.2863 & 0.0160 & 17.9598 & 0.0000 \\
\hline $\begin{array}{l}\text { Tingkat_Kehadiran <- } \\
\text { Kepuasan }\end{array}$ & 0.4133 & 0.4150 & 0.0277 & 14.9317 & 0.0000 \\
\hline penghargaan <- Motivasi & 0.2925 & 0.2926 & 0.0185 & 15.7722 & 0.0000 \\
\hline
\end{tabular}

\section{Indirect Effect}

Indirect Effect berfungsi untuk menguji apakah ada pengaruh tidak langsung. Dari hasil tabel di bawah ini dapat disimpulkan bahwa motivasi memiliki pengaruh tidak langsung ke prestasi. Kesimpulan ini diambil dengan mempertimbangkan nilai p_value sebesar 0.0002 dimana nilai ini kurang dari 0.05 . 
Tabel 2 indirect efect

\begin{tabular}{|l|l|l|l|l|r|}
\hline & $\begin{array}{l}\text { Original } \\
\text { Sample (O) }\end{array}$ & $\begin{array}{l}\text { Sample } \\
\text { Mean (M) }\end{array}$ & $\begin{array}{l}\text { Standard } \\
\text { Deviation } \\
(\text { STDEV) }\end{array}$ & $\begin{array}{l}\text { T Statistics } \\
(|\mathrm{O} / \mathrm{STDEV}|)\end{array}$ & P Values \\
\hline Kepuasan -> Prestasi & & & & & \\
\hline Motivasi -> Kepuasan & & & & & \\
\hline Motivasi -> Prestasi & 0.2020 & 0.2028 & 0.0531 & 3.8039 & 0.0002 \\
\hline
\end{tabular}

\section{R Square}

Kriteria kebaikan model dalam PLS yang pertama dapat dilihat dari nilai R-square seperti yang disajikan pada tabel di bawah ini.

Tabel 3 R-square

\begin{tabular}{|l|r|r|r|r|r|}
\hline & $\begin{array}{l}\text { Original } \\
\text { Sample } \\
(\mathbf{O})\end{array}$ & $\begin{array}{l}\text { Sample } \\
\text { Mean } \\
(\mathbf{M})\end{array}$ & $\begin{array}{l}\text { Standard } \\
\text { Deviation } \\
(\text { STDEV })\end{array}$ & $\begin{array}{l}\text { T Statistics } \\
(\mid \mathbf{O} / \mathbf{S T D E V})\end{array}$ & P Values \\
\hline Kepuasan & 0.4582 & 0.4754 & 0.0819 & 5.5929 & 0.0000 \\
\hline Prestasi & 0.7378 & 0.7476 & 0.0467 & 15.7983 & 0.0000 \\
\hline
\end{tabular}

Berdasarkan tabel di atas, dapat dilihat bahwa nilai R-square untuk kepuasan sebesar 0.458. Nilai ini memperlihatkan bahwa variable motivasi dapat menjelaskan sebesar $45.8 \%$ dari seluruh data pada variable kepuasan.

Sedangkan nilai R-Square sebesar 0.738 untuk variable prestasi menunjukkan bahwa variable motivasi dan variable kepuasan mampu menjelaskan sebesar $73.8 \%$ dari seluruh keragaman data pada prestasi.

\section{Average Variance Extracted (AVE)}

AVE merupakan uji statistic untuk menguji validitas dari indicator-indikator yang menyusun setiap variable laten. Nilai AVE untuk kepuasan sebesar 0.682, motivasi sebesar 0.5896, dan prestasi sebesar 0.6854 .

Tabel 4 Average Variance Extracted (AVE)

\begin{tabular}{|l|r|r|r|r|r|}
\hline & \multicolumn{1}{|l|}{$\begin{array}{l}\text { Original } \\
\text { Sample (O) }\end{array}$} & $\begin{array}{l}\text { Sample } \\
\text { Mean (M) }\end{array}$ & $\begin{array}{l}\text { Standard } \\
\text { Deviation } \\
\text { (STDEV) }\end{array}$ & $\begin{array}{l}\text { T Statistics } \\
(\text { (O/STDEV })\end{array}$ & P Values \\
\hline Kepuasan & 0.6842 & 0.6851 & 0.0426 & 16.0660 & 0.0000 \\
\hline Motivasi & 0.5896 & 0.5932 & 0.0373 & 15.7971 & 0.0000 \\
\hline Prestasi & 0.6854 & 0.6880 & 0.0438 & 15.6467 & 0.0000 \\
\hline
\end{tabular}


Nilai minimal untuk AVE adalah 0.5. Berdasarkan hasil diatas, dapat disimpulkan bahwa indicator-indikator pertanyaan dalam model telah valid karena memiliki nilai AVE diatas 0.5

\section{Composite Reliability}

Composite reliability berfungsi untuk menguji keandalan kuesioner yang telah dibuat. Nilai composite reliability setiap variable laten adalah untuk kepuasan 0.8664 , motivasi sebesar 0.8763 , dan prestasi sebesar 0.9158 . Hasil composite reability akan menunjukan nilai memuaskan jika diatas 0,7.

Tabel 5 Composite Reliability

\begin{tabular}{|l|r|r|r|r|r|}
\hline & \multicolumn{1}{|l|}{$\begin{array}{l}\text { Original } \\
\text { Sample (O) }\end{array}$} & \multicolumn{1}{|l|}{$\begin{array}{l}\text { Sample } \\
\text { Mean (M) }\end{array}$} & $\begin{array}{l}\text { Standard } \\
\text { Deviation } \\
\text { (STDEV) }\end{array}$ & \multicolumn{1}{|c|}{$\begin{array}{l}\text { T Statistics } \\
(\mid \mathbf{O} / \text { STDEV } \mid)\end{array}$} & P Values \\
\hline Kepuasan & 0.8664 & 0.8659 & 0.0235 & 36.9380 & 0.0000 \\
\hline Motivasi & 0.8763 & 0.8767 & 0.0173 & 50.7562 & 0.0000 \\
\hline Prestasi & 0.9158 & 0.9158 & 0.0160 & 57.3145 & 0.0000 \\
\hline
\end{tabular}

\section{Cronbach alpha}

Uji reliabilitas juga dapat dilihat dari nilai Cronbach alpha setiap variable laten.

Tabel dibawah ini memberikan hasil Cronbach alpha setiap variable laten.

Tabel 6 Cronbach Alpha

\begin{tabular}{|c|c|c|c|c|c|}
\hline & $\begin{array}{l}\text { Original } \\
\text { Sample (0) }\end{array}$ & $\begin{array}{l}\text { Sample } \\
\text { Mean (M) }\end{array}$ & $\begin{array}{l}\text { Standard } \\
\text { Deviation } \\
\text { (STDEV) }\end{array}$ & $\begin{array}{l}\text { T Statistics } \\
(|\mathrm{O} / \mathrm{STDEV}|)\end{array}$ & P Values \\
\hline Kepuasan & 0.7681 & 0.7663 & 0.0474 & 16.2216 & 0.0000 \\
\hline Motivasi & 0.8207 & 0.8204 & 0.0289 & 28.3673 & 0.0000 \\
\hline Prestasi & 0.8851 & 0.8848 & 0.0239 & 37.0632 & 0.0000 \\
\hline
\end{tabular}

Dari hasil diatas dapat disimpulkan bahwa setiap variabel telah reliabel karena nilai alpha Cronbach yang dihasilkan lebih besar dari 0.6. 


\section{SIMPULAN \& SARAN}

\section{Simpulan}

Penelitian ini bukti empiris mengenai pengaruh motivasi dan kepuasan terhadap prestasi. Penelitian ini menggunakan sampel 100 responden yang merupakan dosen universitas kadiri.

Hasil penelitian menunjukkan bahwa :

1. Motivasi berpengaruh terhadap kepuasan dimana motivasi yang efektif dapat meningkatkan atau mendorong seorang dosen merasa puas

2. Motivasi berpengaruh terhadap prestasi. Dimana seorang dosen yang memiliki komitmen terhadap organisasi akan merasa bahagia menjadi bagian dari organisasi tersebut, mempunyai kepercayaan dan perasaan yang baik terhadap organisasiny dan memiliki keinginan untuk tetap tinggal dalam organisasi, serta bermaksud untuk melakukan apa yang terbaik bagi organisasi sehingga akan lebih memunculkan prestasi.

3. Kepuasan berpengaruh terhadap prestasi. Dimana kepuasan dapat meningkatkan atau mendorong seorang dosen memiliki prestasi kerja yang baik.

\section{Saran}

Berdasarkan hasil penelitian yang telah dilakukan, ada beberapa saran yang dapat dipertimbangkan untuk penelitian selanjutnya, yaitu :

1. Penelitian selanjutnya diharapkan dapat melakukan penelitian di semua unit institusi sehingga hasil penelitian lebih menyeluruh.

2. Penelitian selanjutnya diharapkan dapat melakukan pengujian dengan model yang lebih dikembangkan, sehingga hasil penelitian dapat lebih memberi gambaran yang lebih baik.

\section{DAFTAR PUSTAKA}

Arikunto, S. 2006. Prosedur Penelitian, Suatu Pendekatan Praktik. Jakarta : Rineka Cipta

Berelson dan Steiner. 2003. Consumer Behaviour Implication, Business Publication Inc. Dallas Texas

Danim, Sudarman. 2004. Motivasi Kepemimpinan dan Efektivitas Kelompok. Jakarta : Rineka Cipta 
Ghozali. 2007. Aplikasi Analisis Multivariat dengan Program SPSS. Semarang : Badan Penerbit Universitas Diponegoro

Hasibuan, M.S.P. 2003. Manajemen Sumber Daya Manusia. Jakarta : PT Bumi Aksara

Ishak, Arep. 2003. Manajemen Motivasi. Jakarta : PT gramedia Widiasarana

Kreitner, Robert and Angelo Kinicki. 2001. Organizational Behaviour. Fifth Edition. Irwin McGraw-Hill

Mangkunegara, , A.A. Anwar Prabu. 2005. Evaluasi Kerja SDM. Bandung : Refika Aditama

Nasution, M.N. 2005. Total Quality Management. Jakarta : PT Gramedia Pustaka Utama

Robbins. 2003. Perilaku Organisasi. Jakarta : PT Salemba Empat

Sutrisno, Edy. 2011. Manajemen Sumber Daya Manusia. Jakarta : Kencana

Wursanto, Ig. 2002. Dasar-Dasar Ilmu Organisasi. Yogyakarta : Andi

Handoko, T.Hani, Manajemen Personalia dan Sumberdaya Manusia, Ed.II, Cet.ke15, Yogyakarta: BPFE Yogyakarta, 2001.

Mangkunegara, Anwar Prabu, Evaluasi Kinerja SDM, Cet.ke-2, Bandung: PT Refika Aditama, 2006.

— Manajemen Sumber Daya Manusia Perusahaan, Cet.ke-7, Bandung: PT Remaja Rosdakarya, 2007.

Kreitner and Kiricki, Manajemen Pemasaran: Analisis, Perencanaan, Implementasi, dan Kontrol, Perjemahan Hendra Teguh dan Ronny A. Rusli, Jilid I, Jakarta: Prenhallindo, 1997.

Siagian, Sondang P. 2006. Manajemen Sumber Daya Manusia. Jakarta: PT Bumi Aksara.

Frederick herzberg F. Work and the natural of man, cleveland, $\mathrm{OH}$ : work publishing company

Clayton P. Alderfer (2010) teachers' collective efficacy, job statisfaction, and job stress in cross-cultural context, the jurnal of experimental education, 78 PP 464-486

Douglas Perilaku Organisasi Buku 1 dan 2 Jakarta ; Salemba Empat

Keith Davis 1985: 96 industrial salespeople's view on motivation, industrial marketing management 
Harold E Brust dalam Anoraga 2006: 82-83 Kepemimpinan dalam manajemen, jakarta : rineka cipta

Straus dan Sayless, organizational behavior (terjemahan) PT. Bhuana Ilmu Populer, Jakarta

Harirch dan Hulin, Manajemen Kepegawaian, Yogyakarta; Kanisius

Budiyanto. 2013. Pengembangan Organisasi Sektor Publik (Pemerintah) dengan Pendekatan Organizational Citizenship Behavior (OCB). Orasi Ilmiah Dies Natalis Ke 41 STIESA.

Podsakoff, N.P, Blume, B.D Whiting, S.W dan Padsakoff, P.M. 2009. Individual and Organizatio Level Consequencesof Organizational Citizenship Behaviours: A Meta Analysis. Journal of Applied Psychology, 94,122-141

Riketta, M. Dan Landerer, A. 2002. Organizational Commitment, Accountability and Work Behavior: A Correlation Study. Social Behavior and Personality 30 (7): $653-660$ 